Original Research Article

\title{
A comparative study for evaluation of cognitive function in type-II diabetes mellitus patients and non-diabetics
}

\author{
Dulcie Celia A.*, Ezhil Ramya J., Sriviruthi B.
}

Department of Pharmacology, Tirunelveli Medical College, Tirunelveli, Tamil Nadu, India

Received: 26 January 2018

Accepted: 06 March 2018

\section{*Correspondence to:}

Dr. Dulcie Celia A.,

Email: dulcie04@gmail.com

Copyright: (c) the author(s), publisher and licensee Medip Academy. This is an openaccess article distributed under the terms of the Creative Commons Attribution NonCommercial License, which permits unrestricted noncommercial use, distribution, and reproduction in any medium, provided the original work is properly cited.

\begin{abstract}
Background: To evaluate the impact of type-II diabetes mellitus on cognitive function and to assess the factors associated with impaired function.

Methods: This prospective study compared 100 type-II diabetic people attending the diabetic clinic of Tirunelveli Medical College Hospital with another 100 membered control group. The study group was selected randomly between the age group of 45-65 years. A neuro-cognitive assessment was done using Standardized Mini Mental State Examination (SMMSE), which is a simple and reliable screening test. This scale has 12 questions with time limits to assess orientation, memory, calculation, language, attention and construction. Magnitude and severity of cognitive decrement were analysed along with the possible factors affecting it.

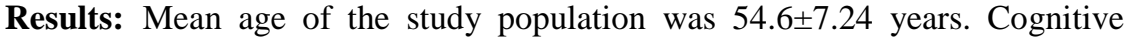
impairment was noted among 62 of cases and 48 of the control group, which means a $14 \%$ higher prevalence of cognitive impairment among the type 2 diabetics. The association of development of cognitive impairment and duration of diabetes mellitus was significant statistically ( $\mathrm{p}$ value $=0.025443 ; \mathrm{p}<0.05$ ). Other demographic variables like gender, education and domicile were also seen to affect the results.

Conclusions: Mild to moderate cognitive impairment was found significantly higher among the type-II diabetics than the non-diabetics. The cognitive impairment was found to be associated with the duration of diabetes. Hence the routine screening of cognition by SMMSE should be done in all type-II diabetic patients.
\end{abstract}

Keywords: Cognitive dysfunction, Standardized Mini Mental State Examination (SMMSE), Type-II diabetes mellitus

\section{INTRODUCTION}

Diabetes mellitus is a heterogeneous metabolic disorder characterized by the common feature of chronic hyperglycaemia with disturbance of carbohydrate, fat and protein metabolism. ${ }^{1}$ The increasing prevalence of diabetes over the world has become an important public health problem. As population is increasing, getting older, more obese and sedentary, the number of individuals with diabetes is also steeply rising.

As of 2010, there were approximately 285 million people diagnosed with diabetes mellitus compared to around 30 million in $1985.2,3$ Developing countries like India and China contribute much to the diabetic load of the world. ${ }^{4}$

Of the two types, Type-II diabetes is more common (90$95 \%$ of all cases) than type 1 and has increased markedly since 1960 in parallel with obesity. ${ }^{4}$ Type-II Diabetes Mellitus is a non-autoimmune, polygenic disease condition in which there is impaired insulin effectiveness (insulin resistance) and abnormal glucose homeostasis.

This form generally manifests in mid-life or beyond with a mean age of about 45 years. ${ }^{1}$ Risk factors include age over 45 years, a positive family history, physical inactivity, low fibre diet, people with impaired glucose 
tolerance or metabolic syndrome, prior gestational diabetes. ${ }^{5}$ The known deleterious effects of diabetes include changes in large and small blood vessels, which in turn can lead to peripheral neuropathy, retinopathy, renal failure, ischaemic heart disease as well as cerebrovascular disease including stroke. ${ }^{6}$

Neurological co-morbidities of diabetes have recently began to attract more interest. They are among the most common but under-recognized complications of diabetes. Several studies have established the relationship between cognitive dysfunction and type-II diabetes. Mild cognitive decline is a natural and inevitable part of growing older. Unfortunately for people with diabetes, the disease accelerates this process. Both extremes of high blood glucose (hyper glycaemia) and low blood glucose (hypo glycaemia) contribute to the development of memory loss among people with Type-II Diabetes Mellitus. This could affect the day-to-day activities of patients. Hence, a preserved cognitive status would help improve the quality of life of patients. Early detection can also help the clinician for a better management of the condition.

Aim of the study was to evaluate the impact of type-II diabetes mellitus on cognitive function and to assess the factors associated with impaired function.

\section{METHODS}

It was a prospective, randomized, comparative study. Study was carried out at Out-patient department, Diabetes Mellitus Clinic, Tirunelveli Medical College Hospital from August 2014-September 2014.

Hundred out-patients of type-II diabetes mellitus who are attending the diabetic clinic. Hundred non-diabetics of the same age group.

\section{Inclusion criteria}

- Known cases of type-II diabetes mellitus for minimum 2 years duration

- $\quad$ Age group-45 to 65 years

- Both genders.

\section{Exclusion criteria}

- Any coexisting medical illness like stroke, hypertension, liver cirrhosis, chronic renal failure, congestive heart failure

- Concurrent medications like sedatives, hypnotics, and anti-depressants

- Psychological disorders/Neurologic disorders

- Alcoholics/smokers/drug abusers

This comparative study was conducted at Tirunelveli Medical College Hospital with the co-operation of Department of Pharmacology and Department of General Medicine after obtaining approval from the Institutional Ethical Committee. Total of 100 type-II diabetes mellitus patients (case group) and 100 non-diabetics (control group) were enrolled in the study. Selection was made randomly, based on the as mentioned criteria and with a written informed consent. After collecting their demographic information, patients were subjected to neuro-cognitive assessment using Standardized Mini Mental State Examination. This scale has 12 questions with time limits to assess orientation, memory, calculation, language, attention and construction (Table 1). Meanwhile, hundred non-diabetics of the same age group and with the same criteria were also assessed to serve as the control group. Scoring was based on 30 total points and less than 26 was considered as impaired. Scores in the range 20-25, 10-19, 0-9 is said to have mild, moderate and severe cognitive impairment respectively. ${ }^{6}$ Statistical representation of data was done. The Chi-square test was used to test the association between the events.

\section{RESULTS}

\section{Demographic variables}

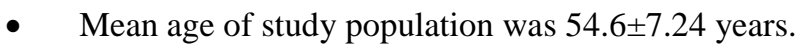

- No significant differences in sex distribution $(\mathrm{p}=0.255)$, educational level $(\mathrm{p}=0.087)$ and domicile $(\mathrm{p}=0.380)$ were found between cases and control (Table 2).

\section{Cognitive analysis}

- $\quad$ Significant cognitive impairment was found among type-II diabetic cases when compared to the control group ( $\mathrm{p}=0.047 ; \mathrm{p}<0.05)$.

- Among the cases, 62 individuals had SMMSE scores $<26$, and among the control group, 48 individuals scored below 26, so categorized as having cognitive dysfunction (Table 3, Figure 1).

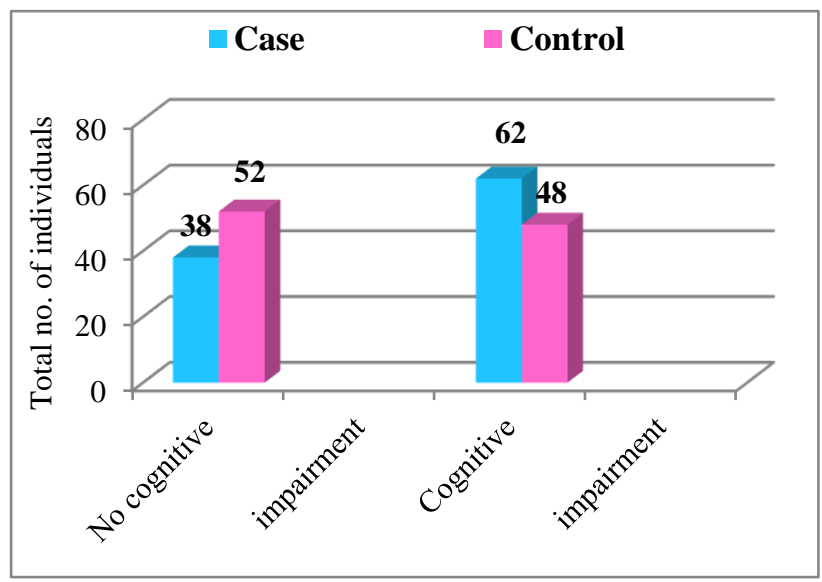

Figure 1: Comparison of cognitive function between cases and control.

Out of these 62 cases, 42 had mild cognitive impairment (scores 20-25), 20 had moderate impairment (scores 1019) and none had severe impairment (scores 0-9) (Table 4, Figure 2). 
Table 1: standardized mini-mental state examination (SMMSE).

\begin{tabular}{|c|c|c|c|}
\hline & Question & Time allowed & Score \\
\hline \multirow{5}{*}{1} & a. What year is this? & 10 seconds & $/ 1$ \\
\hline & b. Which season is this? & 10 seconds & $/ 1$ \\
\hline & c. What month is this? & 10 seconds & $/ 1$ \\
\hline & d. What is today's date? & 10 seconds & $/ 1$ \\
\hline & e. What day of the week is this? & 10 seconds & $/ 1$ \\
\hline \multirow{6}{*}{2} & a. What country are we in? & 10 seconds & $/ 1$ \\
\hline & b. What province are we in? & 10 seconds & $/ 1$ \\
\hline & c. What city/town are we in? & 10 seconds & $/ 1$ \\
\hline & d. IN HOME - What is the street address of this house? & 10 seconds & $/ 1$ \\
\hline & IN FACILITY - What is the name of this building? & & \\
\hline & e. IN HOME - What room are we in? IN FACILITY - What floor are we on? & 10 seconds & $/ 1$ \\
\hline 3 & $\begin{array}{l}\text { SAY: I am going to name three objects. When I am finished, I want you to repeat } \\
\text { them. Remember what they are because I am going to ask you to name them again in } \\
\text { a few minutes. Say the following words slowly at } 1 \text {-second intervals-ball/ car/man }\end{array}$ & 20 seconds & 13 \\
\hline 4 & Spell the word WORLD. Now spell it backwards. & 30 seconds & 15 \\
\hline 5 & Now what were the three objects I asked you to remember? & 10 seconds & 13 \\
\hline 6 & SHOW wristwatch. ASK: What is this called? & 10 seconds & $/ 1$ \\
\hline 7 & SHOW pencil. ASK: What is this called? & 10 seconds & $/ 1$ \\
\hline 8 & SAY: I would like you to repeat this phrase after me: No ifs, ands or buts. & 10 seconds & $/ 1$ \\
\hline 9 & $\begin{array}{l}\text { SAY: Read the words on the page and then do what it says. Then hand the person the } \\
\text { sheet with CLOSE YOUR EYES on it. If the subject reads and does not close their } \\
\text { eyes, repeat up to three times. Score only if subject closes eyes }\end{array}$ & 10 seconds & $/ 1$ \\
\hline 10 & $\begin{array}{l}\text { HAND the person a pencil and paper. SAY: Write any complete sentence on that } \\
\text { piece of paper. (Note: The sentence must make sense. Ignore spelling errors) }\end{array}$ & 30 seconds & $/ 1$ \\
\hline \multirow{2}{*}{11} & $\begin{array}{l}\text { PLACE design, eraser and pencil in front of the person. SAY: Copy this design } \\
\text { please. }\end{array}$ & \multirow[t]{2}{*}{1 minute } & \multirow[t]{2}{*}{$/ 1$} \\
\hline & $\begin{array}{l}\text { Allow multiple tries. Wait until person is finished and hands it back. Score only for } \\
\text { correctly copied diagram with a 4-sided figure between two 5-sided figures. }\end{array}$ & & \\
\hline \multirow[t]{2}{*}{12} & $\begin{array}{l}\text { ASK the person if he is right or left-handed. Take a piece of paper and hold it up in } \\
\text { front of the person. SAY: Take this paper in your right/left hand (whichever is non- } \\
\text { dominant), fold the paper in half once with both hands and put the paper down on the } \\
\text { floor. Score } 1 \text { point for each instruction executed correctly. } \\
\text { Takes paper correctly in hand } \\
\text { Folds it in half } \\
\text { Puts it on the floor }\end{array}$ & \multirow[t]{2}{*}{30 seconds } & $\begin{array}{l}/ 1 \\
/ 1 \\
/ 1\end{array}$ \\
\hline & Total test score & & 130 \\
\hline
\end{tabular}

Table 2: Demographic variables.

\begin{tabular}{|c|c|c|c|c|c|}
\hline Characteristic & Case (N & & Contr & & p-value \\
\hline \multirow{2}{*}{ Gender } & Male & Female & Male & Female & \multirow{2}{*}{0.255} \\
\hline & 48 & 52 & 40 & 60 & \\
\hline \multirow{2}{*}{ Age(years) } & $45-55$ & $56-65$ & $45-55$ & $56-65$ & \multirow{2}{*}{0.138} \\
\hline & 60 & 40 & 70 & 30 & \\
\hline \multirow{2}{*}{ Education } & $<10$ th & $>10$ th & $<10$ th & $>10^{\text {th }}$ & \multirow{2}{*}{0.087} \\
\hline & 50 & 50 & 62 & 38 & \\
\hline \multirow{2}{*}{ Domicile } & Rural & Urban & Rural & Urban & \multirow{2}{*}{0.380} \\
\hline & 34 & 66 & 40 & 60 & \\
\hline
\end{tabular}




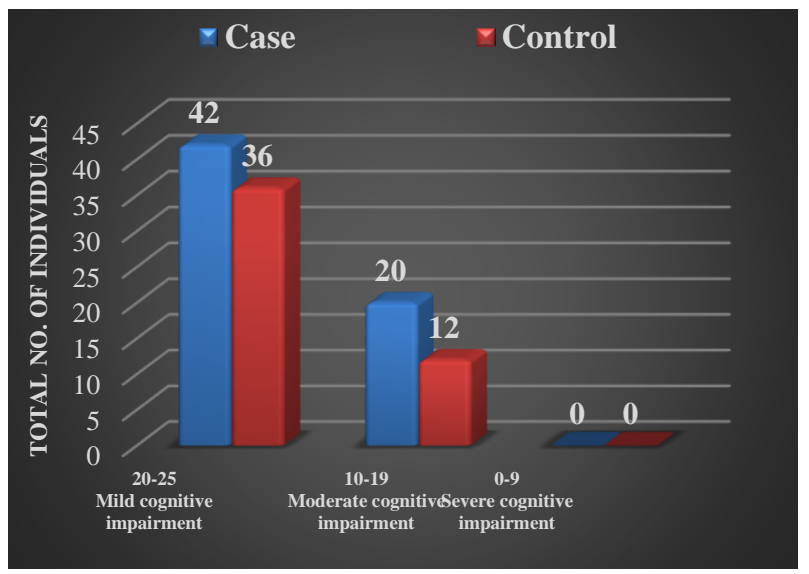

Figure 2: Severity grading of cognitive dysfunction.

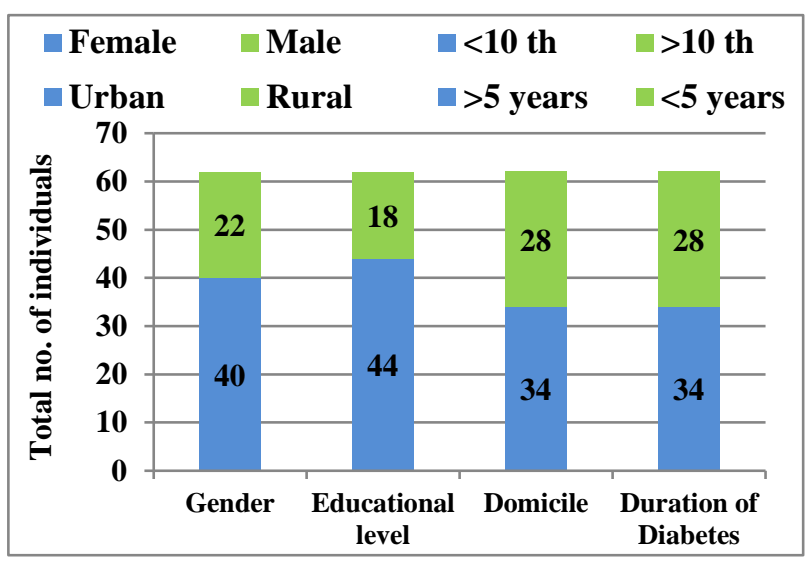

Figure 3: Factors affecting cognitive impairment of cases.

Table 3: Cognitive scores of cases and controls.

\begin{tabular}{|llll|}
\hline Case & $\begin{array}{l}\text { No cognitive } \\
\text { Impairment }\end{array}$ & $\begin{array}{l}\text { Cognitive } \\
\text { Impairment }\end{array}$ & p value \\
\hline Control & 58 & 62 & 0.047 \\
& 52 & 48 & $(<0.05)$ \\
\hline
\end{tabular}

Table 4: Severity of cognitive impairment.

\begin{tabular}{|llll|}
\hline & $\begin{array}{l}\text { 20-25 Mild } \\
\text { cognitive } \\
\text { impairment }\end{array}$ & $\begin{array}{l}\text { 10-19 } \\
\text { Moderate } \\
\text { cognitive } \\
\text { impairment }\end{array}$ & $\begin{array}{l}\text { 0-9 Severe } \\
\text { cognitive } \\
\text { impairment }\end{array}$ \\
\hline Case & 42 & 20 & 0 \\
\hline Control & 36 & 12 & 0 \\
\hline
\end{tabular}

- Incidence of cognitive impairment was found to be greater in females $(\mathrm{p}=0.001 ;<0.01)$ (Figure 3 ).

- Incidence of cognitive impairment was greater among those from urban areas $(\mathrm{p}=0.003 ;<0.01)$.

- Cognitive impairment was also greater among those with low educational levels ( $\mathrm{p}<0.05)$ (Figure 3 ).

- Duration of diabetes mellitus also affected the results. Patients known to be type-II diabetics for more than 5 years had greater incidence of cognitive impairment ( $\mathrm{p}=0.025 ;<0.05$ ) (Figure 3 ).

- Age, drugs and glycaemic control were not found to affect the results ( $>0.05)$.

\section{DISCUSSION}

Cognitive dysfunction is one of the recently established complications of type-II diabetes but this is not usually evaluated in clinical care. This study aims to highlight the association of cognitive impairment with type-II diabetes mellitus, using Standardized Mini Mental State Examination (SMMSE) test, thus providing insight into the magnitude and severity of cognitive decrement with possible factors affecting the scores.

Mild cognitive impairment (MCI) is a common condition that has been recognized as a prodrome to dementia. ${ }^{7}$ Diagnosing MCI is a challenge. Orientation, memory, calculation, language, attention and construction are the various cognitive domains to be assessed. Magnetic Resonance Imaging (MRI), Positron Emission Tomography (PET)scans to assess cerebral function are very expensive and cannot be used as a routine screening test. The Mini-Mental State Examination (MMSE) is the traditionally used simple screening test for cognitive impairment. Standardized Mini-Mental State Examination (SMMSE), an adaptation of MMSE has improved interrater reliability compared with MMSE, taking approximately 10 minutes to administer. ${ }^{8}$

The findings of this study strongly support that there is a significant relationship between cognitive dysfunction and type-II diabetes mellitus. The prevalence of cognitive dysfunction is $14 \%$ higher among type-II diabetics in this study. This is supported by various studies conducted in several places. ${ }^{9-11}$

The following hypotheses suggest the possible mechanisms for development of cognitive impairment with Type -II Diabetes Mellitus. ${ }^{12,13}$

- The oxidative stress created by insulin has detrimental impact on the brain cells.

- The direct effect of diabetes on the vascular system can increase the risk of vascular dementia.

- Metabolism of $\beta$ amyloid protein and presence of APOE $\xi 4$ allele seem to be a more deleterious impact.

- Insulin degrading protein and glycosylation end products also play a contributive role.

The study population included individuals between $45-65$ years for the reason that mean age of occurrence of type-II diabetes is 45 years. ${ }^{1}$ and in the elderly, over 65 years of age, the brain normally undergoes neurodegenerative changes. ${ }^{9}$ Patients with history of smoking, alcoholism, drug abuse, hypertension or any other systemic illness have been excluded since each is an independent risk factor for cognitive impairment and could affect the results. ${ }^{14-16}$ 
According to this study, people with lower educational status scored less (Figure 3). This is similar to another study conducted in India. ${ }^{10}$

Females posed an increased risk that may be due to their lower literacy status (Figure 3).

The affected population was mostly from urban areas (Figure 3) as the diabetic prevalence rate is much more higher in the urban setup.

Longer duration of diabetes was associated with poorer scores (Figure 3) like Nurses' Health Study conducted in U.S. ${ }^{17}$

In contrast to other studies, association between cognitive impairment and glycaemic status could not be proved in this study. ${ }^{18}$ This may be because patients were assessed only by their previous Fasting Blood Sugar values rather than the gold standard $\mathrm{HbA} 1 \mathrm{C}$ as it is expensive.

There is an on-going phase - II trial of Metformin testing whether it could decrease cognitive decline in patients. ${ }^{13}$ Here no correlation was found between pharmacotherapy and SMMSE scores.

This study also has certain limitations. Study population included only 100 patients as the duration of study is shorter. A larger study is required to consolidate the finding that type-II diabetes mellitus patients are more susceptible to cognitive dysfunction. HBA1C can be used as an alternative to fasting blood sugar values to assess the glycaemic control of patients.

\section{CONCLUSION}

Mild to moderate cognitive impairment was found significantly higher among the type-II diabetics than the non-diabetics. The cognitive impairment was found to be associated with the duration of diabetes. This study suggests that the early implementation of Standardized Mini Mental State Examination as a routine ambulatory screening test for type-II diabetes patients can be useful to detect early stages of cognitive impairment.

\section{ACKNOWLEDGEMENTS}

Authors would like to thank the study participants for their cooperation in providing the necessary information.

Funding: No funding sources

Conflict of interest: None declared

Ethical approval: The study was approved by the Institutional Ethics Committee

\section{REFERENCES}

1. Harsh Mohan. Textbook of Pathology. $6^{\text {th }}$ Ed.: Jaypee Brothers Medical Publishers (P) Ltd; 2010:818.
2. Melmed S, Polonsky KS. Larsen PR, Kronenberg HM. William Textbook of Endocrinology. $12^{\text {th }} \mathrm{Ed}$. Philadelphia: Elsevier/Saunders; 2011:1371-1435.

3. Smyth S, Heron A. Diabetes and Obesity: The twin epidemics. Nature Medicine; January 2006;12(1):7580.

4. Iacobuzio-Donahue CA. The Endocrine Pancreas. Robins and Cotran's pathologic basis of disease. $9^{\text {th }}$ Ed. Philadelphia; Elsevier/Saunders; 2015:1105.

5. Goldstein BJ. Dirk Mueller-Wieland. Type-II diabetes: Principles and Practice. $2^{\text {nd }}$ Ed. Crc Press.; 2007:7.

6. National Ageing Research Institute. Final Report: The Assessment of Older People with dementia and depression of Culturally and Linguistically Diverse Backgrounds: A review of current practice and the development of guidelines for Victorian Aged Care Assessment Services. Final Report, July 2011. Available

at: https://www2.health.vic.gov.au/Api/downloadmedia/ \%7B506DB4FF-039F-4753-88E2-

61F4E76448D6\%7D. Accessed 18 June 2014.

7. Morris JC, Storandt M, Miller JP, McKeel DW Jr, Price JL, Rubin EH, and others. Mild cognitive impairment represents early-stage Alzheimer's disease. Arch Neurology. 2001;58:397-405.

8. William Molloy D, MB, MRCPI, FRCPC1, Timothy IM Standish, Lewis DL, PhD_Can J. Screening for Mild Cognitive Impairment Psychiatry. January 2005;50(1)

9. Beeri MS, Goldbourt U, Silverman JM, Noy S, Schmeidler J, Ravona-Springer R, et al. Diabetes mellitus in midlife and the risk of dementia three decades later. Neurology. 2004 Nov 23;63(10):19027.

10. Kataria L, Pandya H, Shah S, Shah H, Gerg R. (India): Prevalence and pattern of cognitive dysfunction in type-II diabetes mellitus. International Journals of medical and applied sciences. ISSN:2320-3137.

11. Alencar RC. (Brazil). Assessment of cognitive status in patients with type -II diabetes mellitus through MMSE. Diabetology and Metabolic syndrome. 28 Jan 2010.

12. Smith GE, Bondi MW. Mild Cognitive Impairment and Dementia: Definitions, Diagnosis, and Treatment. AACN/Oxford Workshop Series; 2013:238.

13. Luchsinger JA. Type-II Diabetes and cognitive impairment linking mechanisms. PMC June 12, 2012.

14. Knut-Olaf H, Groneberg D. Tobacco or Health?: Physiological and social damages caused by tobacco smoking. $2^{\text {nd }}$ Ed. Springer; 2010:160.

15. Harward MP, Udden MM. Medical Secrets. $5^{\text {th }}$ Ed. Mosby Elsevier; 2011:544.

16. Prisant ML. Hypertension in the elderly. Humana Press; 2005:272.

17. Colditz GA, Manson JE, Hankinson SE: The Nurses' Health Study: 20 year contribution to the understanding of health among women. J. Women's Health. 1997;6:49-62. 
18. Reaven GM, Thompson LW, Nuhan D, Haskins E. Relationship between hyperglycemia and cognitive function in older NIDDM patients. Diabetes care. 1990;13:16-21.
Cite this article as: Celia DA, Ramya EJ, Sriviruthi B. A comparative study for evaluation of cognitive function in type-II diabetes mellitus patients and nondiabetics. Int J Basic Clin Pharmacol 2018;7:738-43. 